\title{
Gender Differences in Marital Adjustment, Mental Health and Frustration Reactions during Middle Age
}

\author{
${ }^{1}$ Dr. Shikha Goel, ${ }^{2}$ Dr. Darshan Kaur Narang \\ 1,2Department of Home Science, University of Rajasthan, Jaipur (Rajasthan)
}

\begin{abstract}
The present research was taken up with broad objective to study the marital adjustment, mental health and frustration reactions males and females of middle age from Delhi, India. The sample comprised of 150 males and 150 females $(n=300)$ which are bank employees, doctors and lecturers, within the age range of 40-55 years from Delhi, India. It was seen that Females showed high level of recreational adjustment as compared to males but males were having better group oriented attitude than females.
\end{abstract}

Keywords: India, Marital adjustment, Mental health, Frustration Reaction, Middle age.

From birth, human beings go through a series of transitions that have been referred to variously as "stages," "passages," and "seasons." These terms typically define a specific time period with physical, mental, behavioural or other characteristics that are presumed to characterize, that period. "Adulthood" or "Middle age" is one of them. Middle age is generally considered to extend from age forty to age 60 year. It is an especially difficult time in one's life; adjustment to it is greatly dependent on the foundation laid earlier. The period of middle age is typically marked with physical changes; as, well as new responsibilities of caring for younger children and grand children, and also older parents. A central issue in the lives of young adults in the anxiety and anticipation of a "mid-life transition" as they enter middle adulthood. Marriage is one of the most important events of a person's life. Marriage is a social security for all the individuals, i.e. society through marriage system provides security of needs and cares thereby its existence and prosperity is secured. Marriage is for pleasure, happiness and peace of mind on account of satisfaction through interactions with others, trust, understanding and fulfilling social obligations and enriching personality development. A marriage relationship is a delicate, Kaleidoscopic and complex phenomena. It may be very difficult to disentangle anyone particulars casual element. Besides Marital Satisfaction or dissatisfaction or "Marital Adjustment or Maladjustment," "mid-lifecrisis" also have some other thoughts to include: Worries about the future, inability to enjoy leisure time, a feeling that health is deteriorating, a negative evaluation of work life, and stress arising from taking care of the elderly.

\section{Rational}

Human beings constantly have to adjust to various roles, environmental demands and pressures. Throughout the course of life, human beings strive for well-being and happiness in various spheres of life personal, social, economic, marital and work. Achievement and success in these spheres lead to satisfaction in life, whereas inadequacy to do the same leads in frustration. In the present modern era, professionals like bank employees, doctors and lecturers have to spend more time at their work place and are more indulge in activities related to their career and professions. They have less time to fulfil their family responsibilities which may lead to dissatisfaction. Marital maladjustments are the consequences of dissatisfaction, especially in middle aged couples (40-55 years) who are becoming more inclined towards extra-marital relationships and divorce. So, researcher was interested to know about the factors influencing the marital adjustment during middle age as well as the mental health of couples and also to explore how they react in frustrated situations.

\section{Marital Adjustment}

Marital adjustment is a life longs process; although in the early days of marriage one has to give serious consideration. As Lasswell (1982) points out, "understanding the individual trait of the spouse is an ongoing process in marriage; because even if two people know each other before or at the time of marriage, there is a possibility that people change during the life cycle. Marital adjustment, therefore, calls for maturity that accepts and understands growth and development in the spouse. If this growth is not experienced and realized fully, death in marital relationship is inevitable. Sinha and Mukerjee (1990) defines marital adjustment as, "the state in which there is an over all feeling between husband and wife, of happiness and satisfaction with their marriage and with each other." It, therefore, calls experiencing satisfactory relationship between spouses characterized by mutual concern, care, understanding and acceptance. Sexual compatibility and mutual enjoyment is an important factor contributing to the success of most marital relationship, Job of spouse, shape families in a variety of ways. 
Two major aspects of work directly affect family life: (1) the level of economic rewards associated with work and (2) the conditions associated with performing a job.

Marital Conflicts - No matter how satisfactory and inevitable marriage is, some conflict theorists assert that marital relationships reflect and reinforce gender inequalities (Degler, 1980). Examples that support such an assertion are: (1) until the past few years, a husband could rape his wife and not be charged; (2) in traditional marriage vows the bride is given away to the groom; and (3) the woman has traditionally taken the surname of the husband after marriage. Conflict theory helps to explain the extent of violence in families, where care and cooperation are supposed to exist $\neg$ something not easily explained by functionalist theory. Good communication skills do not prevent conflict. Actually a conflict, followed by a confrontation, can produce positive results.

Fujihara (1998) did a study on 153 married couples which showed that marital adjustment was significantly correlated with subcategories of social adjustment (1) household adjustment (except the spouse), (2) external family adjustment, (3) work adjustment, (4) social leisure adjustment and (5) general adjustment. Thus, marital adjustment may be a part of social adjustment for women, but the two may be discrete for men. A study, made on 1,609 couples from the Russian Army, found that marital dissatisfaction from husband will cross over to the wife directly, whereas the indirect crossover, when a stressor, such as economic hardship or a negative life event increases the strain of a partner, is mediated the impact of the wife's social undermining behaviour on her husband (Westman, Vinokur, Hamilton \& Roziner, 2004).

Eng, Kawachi, Fitzmaurice and Rimm (2005), studied 38,865 men aged (40-75) to examine the affect of change in marital status on health behaviours among men and found Marital termination (Remarriage, widowhood and unmarried) may adversely affect health and dietary behaviours of men.

Vohs, Catanese, and Baumeister (2004) ended that, consistent with the traditional sexual script, research has consistently shown that men have a stronger sexual motivation than do women. Further, Sprecher (2002) found that relationship satisfaction (but not sexual satisfaction) negatively predicted the likelihood of relationship breakup for women but not for men. In contrast, sexual satisfaction (but no relationship satisfaction) negatively predicted the likelihood of relationship dissolution for men but not for women. Thus, perhaps for men decreased sexual satisfaction leads to decreased relationship satisfaction, whereas for women, the reverse is true.

\section{Mental Health}

The concept of mental health includes subjective well-being, perceived self-efficacy, autonomy, competence, intergenerational dependence, and self-actualization of one's intellectual and emotional potential among others. From a cross-cultural perspective it is nearly impossible to define mental health compressively. Mental health is a state of well being in which the individual realizes his or her own abilities, can cope with the normal stresses of life, can work productively, fruitfully and is able to make a contribution to his/her community (The world health reports 2001). Mental health covers an elusive and diffuse field and the term in itself encompasses a multiplicity of meaning.

Blanofield (1967) defined mental health as a composite of attitude towards oneself, ability to realize once potential through action, degree of independence form social influence and the ability to perceive realistically the world around. Fergson (1965) stated that mental health is the ability to cope with one's environment in such a way that one's institutional drives are gratified. They considered that mental illness and mental health, are two opposite ends of the continuum on which any individual can be placed depending on the soundness of his mind. There is a general agreement that two terms mental health and mental illness refer to behaviors which are interpersonal in nature and to mental illness is judged to be dysfunctional according to the norms of an observer.

Matsuoka (1996) conducted a study on 58 middle aged people to determine the degree to which family cohesion accounted for different outcome measures of mental health among native Hawiian families on an island on the verge of major tourism development. This development will cause economic changes that will pose major challenges for the native agrarian families. A series of interviews of focus groups elicited qualitative information on the relationship between family cohesion and mental health. The findings show a clear relationship between family cohesion and mental health status.

Willitts, Benzeval, and Stansfeld (2004) interviewed 2127 men and 2303 women aged less than 65 to describe the .mental health of men and women with differing histories of partnership transitions. They came to the conclusion that partnership protects mental health. The negative outcomes of splitting partnership for health are long lasting in women.

Tiffin, Pearce and Parker (2005) studied 503 subjects from a birth cohort to investigate the affect of socio-economic status throughout the life course on self reported mental health at age 50 years and land up with he conclusion that a downward socio-economic trajectory over the whole life course is associated with poorer self reported mental health in men but not in women. 
Research has shown that engaged workers report well mental and psychosomatic health (Demerouti et al., 2001). Furthermore, they exhibit personal initiative, proactive behavior and learning motivation (Sonnentag, 2003; Schaufeli and Salanova, 2007).

\section{Frustration Reactions}

We are often unable to satisfy our desires or accomplish our goals. Sometimes our ambitions exceed our abilities, or we misperceive the possibilities. But sometimes we are blocked by an external barrier that precludes gratification. Frustration refers to the thwarting or delaying of some ongoing course of action or goal gratification. Frustration is a broad term, it refers to the situation which produced thwarting or the psychological effects of this situation, as when someone is frustrated tends to react with anger, withdrawal depression, or distress. Frustration is an important component of psychological stress, since virtually any seriously harmful condition will thwart important needs and goals and will requires some adjective activity to repair the damage, if possible.

Frustration has been defined in various ways by various psychologists. Most of the definitions agree in stressing the role of interference in goal response in producing frustration.

Rosenzweig (1944) defines frustration as "frustration occurs, whenever the organism meets a more or less insurmountable obstacle or obstruction in its route to the satisfaction of any vital need." Dolland et al (1939) defined frustration as "an interference with the occurrence of an instigated goal response at its proper time in the behaviour sequence."

Obstacles of many kinds cause frustration. A useful distinction can be made between external and personal sources of frustration.

External frustration is based on conditions outside of the individual that impede progress towards a goal. All of the following are external frustrations: getting stuck with a flat tire; having a marriage proposal rejected. In other words external frustrations are based on delay, failure, rejection, loss and other direct blocking of motives. External obstacles can be either social or non-social. Frustration usually increases as the strength, urgency, or importance of a blocked motive increases.

Motivation becomes stronger as we near a goal. Frustration is more intense when a person runs into an obstacle very close to a goal. Personal frustrations are based on personal characteristics; Frustration is actually based on personal limitations. Yet failure may be perceived as externally caused.

All individuals at one time or another, in greater or lesser amount, have to tolerate frustration in their life. The term, frustration tolerance, refers to the amount of stress one can tolerate before his integrated functioning is seriously impaired. Thus frustration tolerance refers to the capacity of the individuals to show persistence in efforts despite repeated failures and antagonistic environment to maintain the integration of the personality.

The person who continues his/her efforts may be said to have more frustration tolerance than the one who discontinues his/her efforts or indulges in any reactionary mode of behavior. In ability to tolerate frustration leads to mental breakdown, maladjustment and problems in also personal relationship. The low frustration tolerance also leads to antisocial behaviour or in other maladaptive behavior.

Anupama Shah et al (1992), to asses the problems faced by unmarried women and their self-perception conducted a research study on 116 un-married women founded by ICSSR on single women, in Baroda. It was found that the unmarried women faced a lot of psychological and emotional problems. They had insecure feeling regarding old age, loneliness and $34 \%$ of the respondents reported frustration with life.

Dill, Jody and Anderson, Craig (1996) tested Berkowitz's reformulation of the frustration aggression hypothesis which states that any negative or aversive stimulus such as frustration, even if justified, will result in same measurable tendency to aggress. 34 college students served as selected samples. Degree of hostile, aggression directed at the frustrating individual was measured. As predicted, justified frustration produced less hostile aggression than unjustified frustration but even justified frustration produced more hostile, aggression than no frustration at all. Result support Berkowitz's frustration aggression reformulation. Findings were also consistent with the view that frustration induces negative affect, which in turn, increases hostility toward the experimenter.

\section{Hypothesis}

On the basis of the previous researches the hypothesis tested in this study are as follows:

- $\quad$ Significant sex difference will be found in marital adjustment of males and females of middle age.

- $\quad$ Significant sex difference will be found in mental health of males and females of middle age.

- $\quad$ Significant sex difference will be found in frustration reactions of males and females of middle age.

$\bullet$ 


\section{Methodology}

The sample comprised of 150 males and 150 females $(\mathrm{N}=300)$ which are bank employees, doctors and lecturers within the age range of 40-55 years, selected through convenient sampling technique. The data were collected from Delhi state, India.

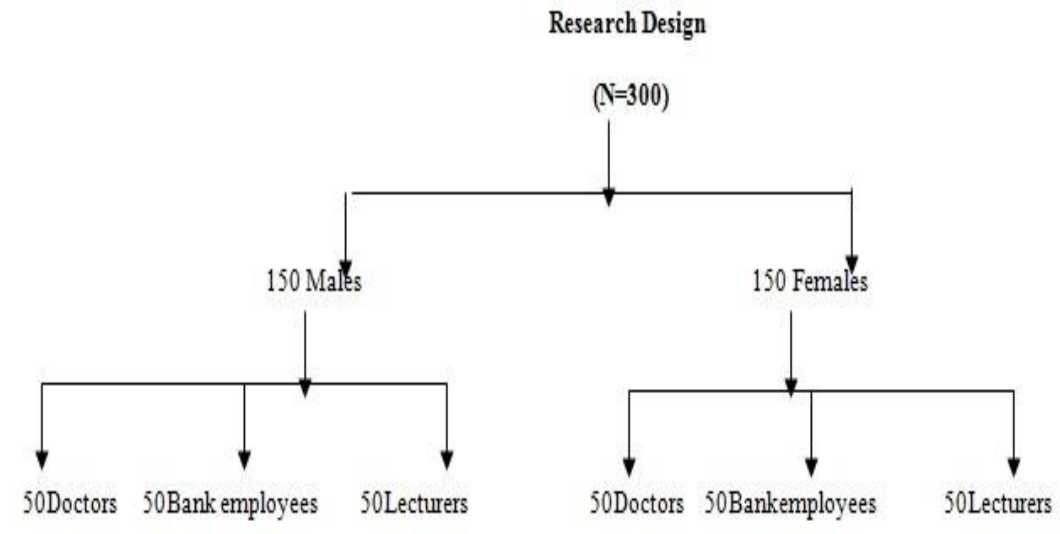

\section{The Following Statistical Tests Were Computed:}

- $\quad$ Mean and Standard Deviation were computed.

- $\quad$ Pearson's 'r' was computed.

Criteria For Sample Selection

- $\quad$ Males and females must belong to the upper middle socioeconomic status.

- $\quad$ The age range of the subject should fall between (40-55 years).

- $\quad$ Minimum working hours of men and women should be 6 to 8 hours per day.

- $\quad$ subject must be either doctors or lecturer or working with the banks only.

\section{Tools For Measurement}

Two tools were used for the measurement of the Marital adjustment and Mental health. Those are:

\section{Marital Adjustment Questionnaire}

Marital Adjustment Questionnaire was developed by the researcher (2004) to assess the marital adjustment in the couples during middle age. Pilot study was conducted by researcher on the $10 \%$ subjects of total sample $(\mathrm{N}=20)$ of the research. Necessary corrections were made to tool after the pilot study. The reliability and validity scores respectively are .96 and .74 . Some basic needs of successful marriage during middle age were used as points of references for rating. Those are Family adjustment, financial adjustment, Emotional adjustment, Sexual adjustment, Recreational adjustment, Role distribution, Social adjustment. Marital adjustment questionnaire consisted of 42 items with a five point scale. Items of the scale are in statement form seeking information for each in any of the five options, which are "Very Rare", "Rare", "Sometimes", "Often", and "Very often". The weight given is 1,2,3,4 and 5 respectively. The test is having reverse key also. Higher the score higher is the adjustment, lower the score poor will be the adjustment.

\section{Mental Health Inventory}

Mental Health Inventory is a self-reporting four point scale and developed by Dr. Jagdish and Dr. A.K. Srivastava (1984). Validity and reliability of Mental Health Inventory is .54 and .73 respectively. The six dimensions have been inculcated in the scale are Positive self - evaluation (PSE), Perception of Reality (PR), Integration of Personality (IP), Autonomy (AUTO), Group Oriented Attitudes (GOA), Environmental Mastery (EM). The items of the scale are in statement form seeking information for each in any of the four options, which are Always, Most of Times, Sometimes, and Never. The weight is 4, 3, 2 and 1 respectively. Therefore, the higher the score on the scale, higher the status / level of mental health, or vice versa.

\section{Frustration Reactions Questionnaire}

The frustration reactions questionnaire was developed by the researcher herself to assess the frustration reactions in the subjects during the middle age. Frustration Reactions Questionnaire (FRQ) consisted of 25 items with 3 point scale. The nature of items used in the rating form constitutes its crucial and unique feature. Certain items of behaviour of middle aged people were used as points of references for rating. The reliability and validity scores respectively are .86 and .59 . Item of the scale are in statement form seeking information for each 
in any of the three options i.e. Never, Sometimes and Always. The weightage is 0,1 and 2 respectively. The test is having reverse key also. Highest score that can be obtained is 50 and lowest score is 0 . Therefore, if a respondent is having high score on the scale his / her frustration level is high or vice versa i.e. the lower the score, the lower the frustration level.

\section{Results}

Table 1

Z-Values Of Showing Gender Differences In Marital Adjustment During Middle Aged ( $N=300)$

\begin{tabular}{|c|c|c|c|c|c|}
\hline \multirow{2}{*}{ Variables } & \multirow{2}{*}{ Gender } & \multirow{2}{*}{ Mean } & \multirow{2}{*}{ SD } & \multicolumn{2}{|l|}{$Z$ value } \\
\hline & & & & Calculated & Table \\
\hline \multirow[t]{2}{*}{ FMY } & Male & 24.45 & 3.91 & \multirow{2}{*}{$0.903^{\mathrm{NS}}$} & \multirow{2}{*}{1.96} \\
\hline & Female & 24.84 & 350 & & \\
\hline \multirow[t]{2}{*}{ FIN } & Male & 22.17 & 3.46 & \multirow{2}{*}{$1.02^{\mathrm{NS}}$} & \multirow{2}{*}{1.96} \\
\hline & Female & 22.55 & 2.97 & & \\
\hline \multirow[t]{2}{*}{ EMO } & Male & 22.73 & 2.89 & \multirow{2}{*}{$0.780^{\mathrm{NS}}$} & \multirow{2}{*}{1.96} \\
\hline & Female & 22.99 & 2.88 & & \\
\hline \multirow[t]{2}{*}{ SEC } & Male & 24.39 & 3.16 & \multirow{2}{*}{$1.26 * *$} & \multirow{2}{*}{1.96} \\
\hline & Female & 24.83 & 2.79 & & \\
\hline \multirow[t]{2}{*}{ REC } & Male & 21.87 & 2.99 & \multirow{2}{*}{$2.96 * *$} & \multirow{2}{*}{2.59} \\
\hline & Female & 22.88 & 2.93 & & \\
\hline \multirow[t]{2}{*}{ RD } & Male & 23.46 & 3.17 & \multirow{2}{*}{$0.964^{\mathrm{NS}}$} & \multirow{2}{*}{1.96} \\
\hline & Female & 23.79 & 2.69 & & \\
\hline \multirow[t]{2}{*}{ SOC } & Male & 23.21 & 2.91 & \multirow{2}{*}{$0.715^{\mathrm{NS}}$} & \multirow{2}{*}{1.96} \\
\hline & Female & 23.45 & 2.90 & & \\
\hline
\end{tabular}

(n=100) FMY-family adjustment, FIN- financial adjustment, EMO- emotional adjustment, SEX- sexual adjustment, REC- recreational adjustment, RD- role distribution, SOC- social adjustment

** Significant at .01 level

NS - Non significant

The table depicts that no significant sex differences were found in marital adjustment of males and females of middle aged. Highly significant sex differences have been found in recreational adjustment only. As the calculated $\mathrm{z}$ value of recreational adjustment is (2.96), which is higher than the tabulated $\mathrm{z}$ value (2.59) indicating that females make high level of recreational adjustment than males.

In other dimensions of marital adjustment, no sex difference have been found which is encouraging here to discuss that both the spouses are enjoying equality and equity roles, participate and cooperate in all kinds of responsibilities leading to good marital adjustment.

With regard to the paths to interrole conflict, both work conflict and family conflict had a rather strong direct effect on it. When a person is overloaded by his / her job, the time that he / she can spend on the other life domains will reduce (Greenhaus and Beutell, 1985).

Table 2

Z-Values Showing Gender Differences In Mental Health During Middle Aged ( $=300)$

\begin{tabular}{|c|c|c|c|c|c|}
\hline \multirow{2}{*}{ Variables } & \multirow{2}{*}{ Gender } & \multirow{2}{*}{ Mean } & \multirow[t]{2}{*}{ SD } & \multicolumn{2}{|l|}{$\mathrm{Z}$ value } \\
\hline & & & & Calculated & Table \\
\hline \multirow[t]{2}{*}{ PSE } & Male & 25.95 & 2.57 & \multirow{2}{*}{$.000^{\mathrm{NS}}$} & \multirow{2}{*}{1.97} \\
\hline & Female & 25.95 & 3.21 & & \\
\hline \multirow[t]{2}{*}{ PR } & Male & 17.60 & 2.03 & \multirow{2}{*}{$0.701^{\mathrm{NS}}$} & \multirow{2}{*}{1.97} \\
\hline & Female & 17.43 & 2.24 & & \\
\hline \multirow[t]{2}{*}{ IP } & Male & 17.13 & 2.24 & \multirow{2}{*}{$1.06^{\mathrm{NS}}$} & \multirow{2}{*}{1.97} \\
\hline & Female & 17.41 & 2.32 & & \\
\hline \multirow[t]{2}{*}{ AUTO } & Male & 10.41 & 1.81 & \multirow{2}{*}{$1.93^{\mathrm{NS}}$} & \multirow{2}{*}{1.97} \\
\hline & Female & 10.81 & 1.77 & & \\
\hline \multirow[t]{2}{*}{ GOA } & Male & 21.40 & 2.57 & \multirow{2}{*}{$2.810^{* *}$} & \multirow{2}{*}{2.59} \\
\hline & Female & 20.57 & 2.53 & & \\
\hline EM & Male & 14.60 & 2.58 & $1.54^{\mathrm{NS}}$ & 1.97 \\
\hline
\end{tabular}




\begin{tabular}{|l|l|l|l|l|l|}
\hline & Female & 15.07 & 2.66 & & \\
\hline
\end{tabular}

$(\mathrm{n}=100)$ PSE- positive self evaluation, PR- perception of reality, IP- integration of personality, AUTOautonomy, GOA-group oriented attitude, EM- environmental mastery

* Significant at .05 level

* Significant at .05 level

NS - Non significant

The table reveals the significant sex differences on mental health of middle aged couples. The calculated $\mathrm{z}$ value for group oriented attitude is (2.81) higher than the table value (2.59). So, males are more group oriented than females in middle age.

Table 3

$\mathrm{z}$-values showing gender differences in frustration reactions during middle aged $(\mathrm{N}=\mathbf{3 0 0})$

\begin{tabular}{|l|l|l|l|l|l|}
\hline Variables & Gender & Mean & SD & \multicolumn{2}{|l|}{ Z value } \\
\cline { 3 - 6 } & & & & Calculated & Table \\
\hline \multirow{2}{*}{ Frustration } & Male & 7.26 & 5.52 & $1.71^{\mathrm{NS}}$ & 1.96 \\
\cline { 2 - 5 } & Female & 8.40 & 6.02 & & \\
\hline
\end{tabular}

NS $=$ Non significant

No significant sex differences are found in males and females of middle age regarding frustration. It is observed that there may be many phases where the couples undergo problems, but with their mutual understanding, they understand each other and adjust to the problems well without getting frustrated.

\section{Discussion And Conclusion}

The study hypothesized that " Significant sex difference will be found in marital adjustment of males and females of middle age" and finds partial support for this hypothesis. Working females have to play dual roles as they are employed out side house. They shoulder more responsibilities than males, adjust their time and energy for children, spouse, and household activities, religious and social activities. They seek contentment and recreation out of all these activities performed and makes adjustment accordingly. This can be supported by Powers, Myers and Tingle (2004) studied 83 individuals (42 couples) living in medical marriage. Results revealed that resident spouses scored higher than the general married population on wellness, mattering, and satisfaction with shared marriage values and scored lower on work satisfaction and realistic beliefs. Barling (1986) in a study on "inter role conflict and marital functioning" found that conflict regarding work and family roles was associated with lower levels of marital adjustment among dual earner couples.

Second hypothesis states that "Significant sex difference will be found in mental health of males and females of middle age." and findings partially supports this hypothesis. In Indian culture, females take over all family responsibilities as family is their first priority. Their whole routine revolves around the needs of the family members. Hence, they have less time for group oriented activities as compared to males. If female is employed outside home, the condition even worsens as she has to squeeze on to her personal time to create balance between job and family.

Agresta (2003) reported that female professionals experienced more role discrepancy than did male professionals (e.g. friendship and family network, being in a committed relationship, parenting, community activities). The effective balancing of various professional and personal roles presumably could play a salient role in their level of job satisfaction, life satisfaction and overall well - being (Barnett and Hyde, 2001 ; Frone, 2000 ; Marks, 2001; Moen \& Yu, 2000).

The third hypothesis states that "Significant sex difference will be found in frustration reactions of males and females of middle age."and findings rejects the stated hypothesis. Dubey and Kumar (1986) conducted a study which shows that the current miserable condition of the society and its mental health is alarming; tension and stress have become a part of life. The twentieth century was branched as the age of stress and anxiety. Coping mechanisms of family to adjust because of excessive tension and stress in the society. The cause may vary from faulty learning, confliction objective, and unclear philosophy of life, dualism, false ego and fast changing values. Women who are balanced or committed across roles, regardless of the number of roles they occupy, will likely report greater life satisfaction and mental health (Marks \& MacDermid ; Perry Jenkins, Repetti \& Crouter, 2000). 
Byers (2005) found that relationship of satisfaction partly mediates the association between selfdisclosure and sexual satisfaction. The authors interpreted this finding as showing that self-disclosure leads to greater relationship satisfaction, which in turn, leads to higher sexual satisfaction.

The research can be concluded that:

Females are having better marital adjustment than males. Even if, working females play dual roles and are over burdened but still they try to make adjustments in family and are satisfied and cool under all circumstances. They participate in family matters, cooperate more and make themselves available when ever required for family matters. They try to seek recreation and satisfaction out of successful management.

It is also supported by the following research studies:

Role balance theory acknowledges that different roles might come into conflict with each other, but women's ability to adjust their entire system of roles to accommodate potential conflicts will likely produce more rewarding results (Marks and MacDermid, 1996).

Prior investigators have reported that women balance multiple roles differently then do men and that woman in the workplace are often mothers who face personal and societal ambivalence about the desire to succeed as both a professional and a parent (Marks, 2001; Martire et al., 2001).

In contrast, males are more mentally healthy than females. A great importance of balance of psychic forces in the males showing sound mental health. Ability to understand and to share other people's emotions, the ability to concentrate at work and interest in several activities in middle aged males results in good adjustment with spouse and with the family members. They always have an inner feeling to spend quality time with their spouse, take care of and satisfy sexual needs of the partner. They have concern and feel responsible for needs of the family members and for smooth functioning of the family, they are able to make equal role distribution among the family members. They try to maintain balance between family and society. During middle age the males have less family responsibilities (as the children are grown up or settled down) and would also desire to spend some time for social work or welfare activities. It leads to their over all life satisfaction.

Hill (2005) conducted a study on 1,314 individuals and found that work to family facilitation was positively related to job satisfaction and life satisfaction, and negatively related to individual stress. Family to work facilitation was positively related to marital satisfaction, family satisfaction and life satisfaction, and negatively related to organizational commitment. Working fathers reported long work hours (49 hours / week), major involvement in household responsibilities (46 hours / week), and a work culture less supportive of their family life than working mothers reported. However, working fathers reported less individual stress, and greater family satisfaction, and life satisfaction than working mothers.

\section{Practical Implications Of The Study}

This study has very deep social implications to strength the marital bonds between the working couples. This can help / suggest

1. The middle aged couples to develop patience and tolerance and understanding for each other.

2. The importance of recreation, role distribution for smooth functioning marriage life.

3. Working couples to owe respect and equality rights to each other regarding financial and family matters with special reference to females.

4. The young ambitious working couples with highly demanding jobs in private sector to bring stability in their married life through spending quality time with each other.

\section{SUGGESTIONS}

- This study was conducted to see the middle age crisis in adulthood regarding marital adjustment, mental health and frustration reactions. Further investigation may be undertaken to find out other factors affecting marital adjustment during early and late adulthood.

- Sample of present investigation was drawn only from Delhi State. Further research would be conducted in other states or metro cities, which will cater to the sample of different back grounds.

- Similar research study may be replicated for other professions from public and private sectors to assess the difference. Thus study on wider and varied population may provide richer and more valuable information.

- Further revitalization programmes could be undertaken for the identified marital'ly maladjusted couples.

- Similar research study can be undertaken on a sample belonging to different communities and cultures like Hindu, Muslim etc. 


\section{References}

[1]. Alexander, P.A. (1985) The forgotten other: A study of medical residents' wives (Doctoral dissertation, California school of Professional Psychology). Dissertation Abstracts International, 46 (4B), 1323.

[2]. Barling, J. (1986) "Inter role conflict and marital functioning", Journal of occupational behaviour. 24,18-25.

[3]. Blood, R.O. and Wolfe, D. (1960) "Husbands and Wives: The Dynamics of Marriage Living."New York: Free Press.

[4]. Chiu, R.K. (1998) Relationship among role conflicts, role satisfactions and life satisfaction : Evidence from Hongkong. (www.findarticles.com).

[5]. Demerouti, E., Bakker, A.B., De Jonge, J., Janssen, P.P.M. and Schaufeli, W.B. (2001), "Burnout and engagement at work as a function of demands and control", Scandinavian Journal of Work, Environment \& Health, Vol. 27 ( 4), pp. $279-86$.

[6]. Dill, Jody C. and Anderson (1996) Effects of frustration justification on hostile aggression, Psychological Abstracts, Vol. 83, No. 8,. pp. 45. (Electronic Sources)

[7]. Dolland, J. Doop, L. Miller, N. Mourea, D. \& Sears, R. (1939) Frustration and Aggression, New Haven ; Yale University Press.

[8]. Dubey, S.L. and Kumar, H. (1986) The current mental health state of population. Indian Journal of Clinical Psychology, September, 13 (2), p 115-160.

[9]. Eng P.M., Kawachi I. Fitzmaurice, G. and Rimm, E.B. (2005) "Effects of marital transitions of changes in dietary and other health behaviour in US male health professionals". Journal of epidemiology and Community Health; 59: 870-872.

[10]. Frone, M.R. (2000) Work-family conflict and employee psychiatric disorders. The national comorbidity survey. Journal of Applied Psychology, 85, 888-895 (www.thefreelibrary.com).

[11]. Greenhaus, J.H. and Beutell, N.J. (1985). Source of conflict between work and family roles. Academy of Management Review, 10, 76-88 (http://findarticles.com).

[12]. Hill, E.J. (2005) Work-family facilitation and conflict, working fathers and mothers, work-family stressors and support. Journal of family issues, Vol. 26, No. 6, 793-819 (www.jfi.sagepub.com).

[13]. Keown, C.F. Jr \& Keown, A.L. (1982) "Success factors for corporate women executives", Group and Organizational Studies, 7 (4).

[14]. Kumar, P. and Rohatogi, K. (1984) Certain personality correlates of marital adjustment. The Indian Journal of Social work. Vol38 (b) $67-70$.

[15]. Lasswell, M.E. and Lasswell, T.E. (1982) Marriage and the family. Washington D.C.: Health and Company.

[16]. Mani, P.G. (1984) Making the best or worst marriage is in your hands". Social Welfare, 31 (1), 7-9.

[17]. Marks, S.R. \& MacDermid, S.M. (2000) Multiple roles and the self: A theory of role balance. Journal of Marriage and the family, $58,417-432$

[18]. Marks, S.R. \& MacDermid, S.M. (1996) Multiple roles and the self: A theory of role balance. Journal of Marriage and the family, 58, 417-432 (www.thefreelibrary.com).

[19]. Marks, S.R. (2001) Role balance among white married couples. Journal of marriage and the family, 63, 1088-1098 (www.thefreelibrary.com).

[20]. Martire, L.M. Parris Stephens, M.A. \& Townsend, A.L. (2001) Centrality of women's multiple roles. Beneficial and detrimental consequences for psychological well-being. Psychology and Aging, 15, 148-156 (www.thefreelibrary.com).

[21]. Matsuoka, Jon K. and Benson, Melaine (1996) "Economic Change, Family Cohesion and Mental Health in a Rural Hawaii Community". Families in Society, February, 77 (2), pp. 108-116.

[22]. Moen P., \& Yu, Y. (2000) Effective work / life strategies: working couples, work conditions, gender and life quality. Social problems, 47, 291-326 (www.thefreelibrary.com).

[23]. Neary, Terrence \& Joseph (1985) Change in the process of marital adjustment, vol. 46, (1), p. 1938.

[24]. Olson, D.H.; Rabynsky, C. (1974) Journal of Marriage and Family Vol. 34,224-235.

[25]. Perry-Jenkins, M., Repetti, R.L. \& Crouter, A.C. (2000) Work and family in the 1990's Journal of Marriage and the family 62, 981998 .

[26]. Reddy, C.R. (1986) Changing status of educated working women. A case study Delhi: B.R. Publishing Corporation. pp. 205-224.

[27]. Schaufeli, W.B. and Salanova, M. (2007), "Work engagement: an emerging psychological concept and its implications for organizations", in Gilliland, S.W., Steiner, D.D. and Skarlicki, D.P. (Eds), Research in Social Issues in Management (Volume 5): Managing Social and Ethical Issues in Organizations, Vol. 5, Information Age Publishers, Greenwich, CT, pp. $135-77$.

[28]. Sprecher, S. (2002). Sexual satisfaction in premarital relationships: Associations with satisfaction, love, commitment, and stability. The Journal of Sex Research, 39, 190-196.

[29]. Tiffin P.A., Pearce M.S. and Parker L. (2005) "Social mobility over the life course and self reported mental health at age 50 : prospective cohort study". Journal of epidemiology and community health, $59: 870-872$.

[30]. Vohs, K. D., Catanese, K. R., \& Baumeister, R. F. (2004). Sex in "his" versus "her" relationships. In J. H. Harvey, A. Wenzel, \& S. Sprecher (Eds), Handbook of sexuality in close relationships (pp. 455-474). Mahway, NJ: Lawrence Erlbaum.

[31]. Westman, M. Vinokur, A.D. Hamilton V.L. \& Roziner, I. (2004) "Crossover of Marital Dissatisfaction during Military Down / Sizing Among Russian Army Officers". Journal of Applied Psychology, Vol. 89, 769-779.

[32]. Willitts M., Benzeval M. and Stansfeld S. (2004) "Partnership history and mental health over time". Journal of Epidemiology and Community Health, $58: 53-58$. 